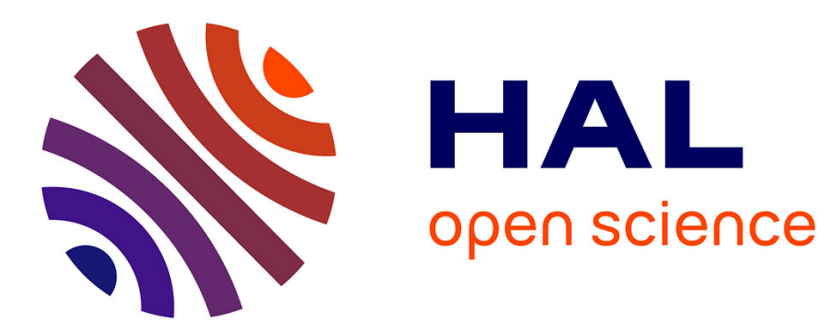

\title{
Sur la machine de Holtz
}

Emeric Dubois

\section{To cite this version:}

Emeric Dubois. Sur la machine de Holtz. J. Phys. Theor. Appl., 1884, 3 (1), pp.260-261. 10.1051/jphystap:018840030026001 . jpa-00238234

\section{HAL Id: jpa-00238234 https://hal.science/jpa-00238234}

Submitted on 1 Jan 1884

HAL is a multi-disciplinary open access archive for the deposit and dissemination of scientific research documents, whether they are published or not. The documents may come from teaching and research institutions in France or abroad, or from public or private research centers.
L'archive ouverte pluridisciplinaire HAL, est destinée au dépôt et à la diffusion de documents scientifiques de niveau recherche, publiés ou non, émanant des établissements d'enseignement et de recherche français ou étrangers, des laboratoires publics ou privés. 


\section{SUR LA MAGHINE DE HOLTZ;}

Par M. E. DUBOIS.

On sait que la machine de Holtz simple cesse d'être amorcée aussitôt que s'arrête le plateau mobile, tandis que, dans une atmosphère convenable, une machine double peut parfois être encore amorcée une demi-heure après qu'on a cessé de faire tourner ce plateau.

Voici comment je propose d'expliquer ces faits. Le papier parchemin qui est l'excitateur d'électricité de la machine n'est pas un parfait conducteur, mais est un médiocre isolant; comme il est terminé par une pointe, il perdra son électricité dans la machine simple dès qu'il cessera de faire fonctionner l'appareil. Mais, dans la machine double, deux papiers se trouvent en présence, les pointes en regard; dès lors, ils fonctionnent comme les deux conducteurs isolés A et B, armés de pointes en regard. Si l'on a 
électrisé de la même manière, positivement par exemple, A et B, la répulsion mutuelle des deux électricités de même nom empêchera l'électricilé de s'échapper par les pointes, et les conducteurs pourront rester électrisés pendant assez longtemps, si l'air est sec et si les supports sont bien isolants.

J'ai vérifié expérimentalement le maintien de la charge sur deux conducteurs isolés, armés de pointes en regard. J'ai pris

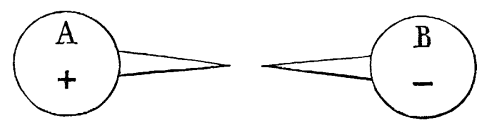

pour cela deux cylindres isolés servant aux expériences fondamentales de l'influence électrique; j'ai fixé à chacun d'eux une épingle avec un peu de cire, les deux pointes se trouvant à $\mathrm{o}^{\mathrm{m}}, \mathrm{o} 2$ de distance. Puis, réunissant ces deux cylindres avec un excitateur à manche de verre, j'ai mis l'un d'eux, avec un excitateur semblable, en communication avec une source intense. J'ai supprimé la communication avec la source, puis la source, et enfin la communication des deux cylindres entre eux, et, pendant un temps assez long, les doubles pendules des cylindres ont continué à diverger. 